\title{
AVALIAÇÃO DO CETOCONAZOL EM CAMUNDONGOS INOCULADOS COM PARACOCCIDIOIDES BRASILIENSIS PELA HISTOPATOLOGIA DE FÍGADO E BAÇO E PELA INTRADERMORREAÇÃO DE PARACOCCIDIOIDINA
}

\author{
Maria do Rosário Rodrigues Silva, Landia Fernandes de Paiva e Rosália \\ Santos Amorim Jesuino
}

\begin{abstract}
Camundongos machos albinos, foram inoculados por via intravenosa com $0,5 \times 10^{7}$ células leveduriformes viáveis de Paracoccidioides brasiliensis da amostra rotulada como $\mathrm{Pb} 2052 \mathrm{e}$ tratados diariamente com cetoconazol nas dosagens de 50 e $100 \mathrm{mg} / \mathrm{kg}$ durante 50 dias e em seguida sacrificados. Observou-se o número de parasitas, formação de granulomas no figado e baço e reação de hipersensibilidade retardada usando-se antígeno de $\mathrm{P}$. brasiliensis preparado segundo Fava Neto, inoculado na pata direita do animal. Verificou-se que: 1. cetoconazol diminuiu acentuadamente o número de parasitas encontrados no fígado e baço; 2. não havia diferença entre o número de granulomas formados no baço e figado de animais tratados e não tratados; 3. a intensidade dos testes cutâneos tardios foram similares em todos os animais.
\end{abstract}

Palavras-chaves: Paracoccidioides brasiliensis, Resposta imune celular. Cetoconazol. Paracoccidioidina.

A paracoccidioidomicose é micose sistêmica, granulomatosa, causada pelo fungo dimórfico, Paracoccidioides brasiliensis. A doença é considerada endêmica na América Latina, sendo que o Brasil, a Colômbia, a Venezuela e Argentina são consideradas regiões de alta prevalência ${ }^{14}$.

$P$. brasiliensis provoca no organismo do animal resposta imunitária muito importante na evolução da doença ${ }^{7}{ }^{10}$. Estudos da imunidade humoral demonstram que em pacientes com paracoccidioidomicose a produção de anticorpos processa-se normalmente, ou mostra-se mais ativa, enquanto a imunidade celular apresenta-se diminuída, principalmente nos casos graves, demonstrado in vivo pela reação de hipersensibilidade retardada frente ao antígeno específico, pela resposta ao dinitroclorobenzeno (DNCB) e pela sobrevivência aos enxertos de pele ${ }^{71213}$.

Departamento de Mic robiologia do Instituto de Patologia Tropical e Saúde Pública da Universidade Federal de Goiás, Goiânia, GO.

Endereço para correspondência: Profa. Maria do Rosário Rodrigues Silva. R. Delenda de Rezende $s / n^{\circ}$, Setor Universitário, 74065-050 Goiânia, GO.

Recebido para publicação em 19/07/93.
Alguns experimentos em camundongos inoculados com $P$. brasiliensis mostram que nestes animais se produzem lesões crônicas, progressivas e generalizadas semelhantes às observadas no homem $^{391015}$.

O tratamento da paracoccidiodomicose com cetoconazol tem sido considerado uma terapia excelente mesmo em indivíduos com a forma grave da doença, sendo que a droga não tem revelado efeitos colaterais significativos ${ }^{11} 14$.

Para verificar o quadro histopatológico do fígado e baço e a resposta da imunidade celular, através da formação de granulomas e hipersensibilidade retardada, em camundongos inoculados com $P$. brasiliensis e tratados com cetoconazol, nos propusemos a fazer o presente trabalho.

\section{MATERIAL E MÉTODOS}

Animais

Foram utilizados 20 camundongos brancos, inbred, machos de 3 a 4 semanas de idade, com 20 a $25 \mathrm{~g}$ de peso. 
Silva MRR, Paiva LF, Jesuino RSA. Avaliação do cetoconazol em camundongos inoculados com Paraccoccidioides brasiliensis pela histopatologia de figado e baço e pela intradermorreação de paracoccidioidina. Revista da Sociedade Brasileira de Medicina Tropical 27:11-14, jan-mar, 1994.

\section{Inóculo}

Foi utilizada amostra de $P$. brasiliensis, obtida no laboratório de Micologia da Universidade Federal de Goiás, rotulada como $\mathrm{Pb} 2052$ cultivada por 8 dias a $37^{\circ} \mathrm{C}$ em agar sabouraud dextrose.

Cada animal recebeu, por via intravenosa, $0,5 \mathrm{ml}$ de suspensão fúngica em salina estéril contendo por $\mathrm{ml} 1 \times 10^{7}$ células leveduriformes viáveis. Os animais controles foram inoculados com o mesmo volume de salina estéril. A viabilidade das células foi verificada através de Janus Green B.

\section{Procedimento experimental}

Os animais foram distribuídos em 4 grupos, rotulados de A a D.

Grupo A: inoculados com $P$. brasiliensis.

Grupo B: inoculados com $P$. brasiliensis e 15 dias depois foram tratados com cetoconazol por via oral com $50 \mathrm{mg} / \mathrm{kg} /$ dia durante 50 dias.

Grupo C: inoculados com $P$. brasiliensis e 15 dias depois foram tratados com cetoconazol por via oral com $100 \mathrm{mg} / \mathrm{kg} / \mathrm{dia}$ durante 50 dias.

Grupo D: animais não infectados e não tratados, usados como controle.

\section{Histopatologia}

Os animais foram sacrificados 72 horas após a última administração da droga. Fragmentos de fígado e baço foram fixados em formalina a $10 \%$, incluídos em parafina e corados pela hematoxilinaeosina (HE) e ácido periódico de Schiff (PAS) para procedimento histopatológico. O número de granulomas e de fungos nos cortes histológicos foi conseguido através de: contagem total na área do corte; projeção da área examinada com câmara clara sobre papel branco comum; transferência do contorno desenhado para papel milimetrado de gramatura uniforme; recorte da área contornada e pesagem; pesagem da área conhecida e inferência do peso por $\mathbf{m m}^{2}$; correlação entre o peso $/ \mathrm{mm}^{2}$ e o peso total para conversão em área total expressa em $\mathrm{mm}^{2}$; correlação entre contagem total/superfície conhecida.

\section{Teste do coxim plantar}

Para o teste do coxim plantar, cada animal recebeu intradermicamente $0,1 \mathrm{ml}$ do antígeno polissacarídico preparado a partir da amostra $\mathrm{Pb}$ 2052, na pata posterior direita, 3 dias antes de serem sacrificados. Leitura foi feita com um paquímetro 48 horas após a inoculação do antígeno. Como controle inoculou-se $0,1 \mathrm{ml}$ de salina na pata posterior esquerda.

\section{Teste estatístico}

Análise estatística foi feita em relação a reação cutânea, ao número de parasitas e de granulomas em animais infectados, infectados e tratados com $50 \mathrm{mg}$ e com $100 \mathrm{mg}$ de cetoconazol, utilizando-se o teste "T" de Student $\alpha=0,05$.

\section{RESULTADOS}

Macroscopicamente observou-se aumento do baço e fígado em 13(93\%) dos 15 animais infectados e microscopicamente a formação de reação inflamatória inespecífica à custa de histiócitos, linfócitos e neutrófilos e uma reação granulomatosa bem definida constituída por macrófagos, células epitelióides e neutrófilos ao redor de grande número de fungos.

As células de $P$. brasiliensis podiam ser vistas isoladas ou agrupadas, livres no parênquima ou dentro de células gigantes ou apresentando-se desprovidas de citoplasma e de núcleo, destacandose pela parede de aspecto duplo, principalmente nos animais apenas infectados (Figuras 1 e 2).

Nos animais tratados, o número de células fúngicas apresentou-se bem reduzido ou ausente. Todos os animais infectados apresentaram-se reatores ao teste do coxim plantar.

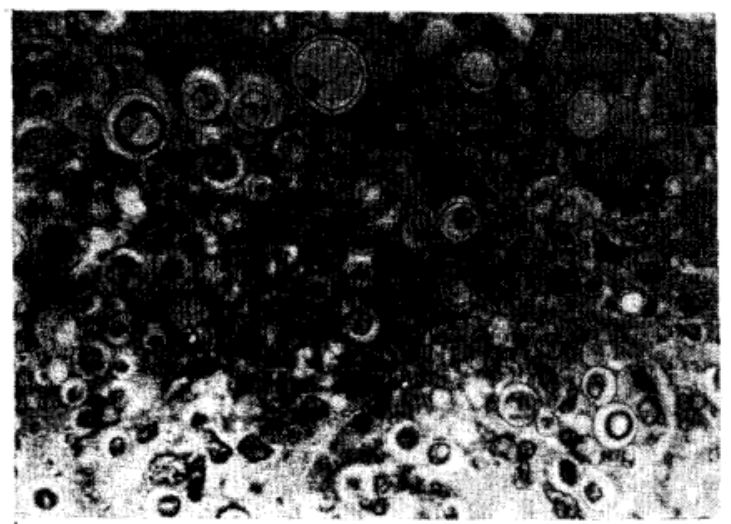

Figura 1 - Numerosas células de P. brasiliensis livres $e$ algumas fagocitadas por células gigantes em animais apenas infectados. 
Silva MRR, Paiva LF, Jesuino RSA. Avaliação do cetoconazol em camundongos inoculados com Paraccoccidioides brasiliensis pela histopatologia de figado e baço e pela intradermorreação de paracoccidioidina. Revista da Sociedade Brasileira de Medicina Tropical 27:11-14, jan-mar, 1994.



Figura 2 - P. brasiliensis no interior de células gigantes em animais infectados e tratados com $50 \mathrm{mg} / \mathrm{kg}$ de cetoconazol.
A Tabela 1 mostra a média do número de parasitas e de granulomas presentes no fígado e baço e os valores médios dos testes cutâneos dos animais estudados.

Com relação ao teste estatístico aplicado verificou-se que: 1 . o grupo de animais infectados mostrou-se com um número de parasitos estatisticamente superior em relação aos grupos infectados e tratados nos dois órgãos examinados e não foi verificada diferença significante entre os grupos infectados e tratados com 50mg e $100 \mathrm{mg}$ de cetoconazol; 2. não houve diferença significante entre os grupos estudados, com relação ao número de granulomas nos dois órgãos; 3. não foi observada diferença significante entre os grupos infectados e infectados e tratados frente ao teste cutâneo com paracoccidioidina.

Tabela 1 - Média geométrica dos testes cutâneos e do número de parasitas e de granulomas presentes no figado e baço de animais infectados com $P$. brasiliensis, infectados e tratados com $50 \mathrm{mg} / \mathrm{kg}$ de cetoconazol e de infectados e tratados com $100 \mathrm{mg} / \mathrm{kg}$ de cetoconazol.

\begin{tabular}{|c|c|c|c|c|c|c|}
\hline \multirow[t]{2}{*}{ Grupos } & \multirow{2}{*}{$\begin{array}{l}\mathrm{N}^{0} \mathrm{de} \\
\text { animais }\end{array}$} & \multicolumn{2}{|c|}{ Parasitas $/ \mathrm{mm}^{2}$} & \multicolumn{2}{|c|}{ Granulomas $/ \mathrm{mm}^{2}$} & \multirow[t]{2}{*}{ Teste cutâneo/mm } \\
\hline & & baço & $\overline{\text { figado }}$ & baço & $\overline{\text { fígado }}$ & \\
\hline Infectado & 5 & 0,448 & 0,704 & 0,070 & 0,114 & 0,84 \\
\hline $\begin{array}{l}\text { Infectado }+ \\
50 \mathrm{mg} \text { de cetoconazol }\end{array}$ & 5 & 0,052 & 0,164 & 0,022 & 0,086 & 0,76 \\
\hline $\begin{array}{l}\text { Infectado }+ \\
100 \mathrm{mg} \text { de cetoconazol }\end{array}$ & 5 & 0,020 & 0,032 & 0,016 & 0,016 & 0,44 \\
\hline
\end{tabular}

\section{DISCUSSÃO}

Os achados histopatológicos no fígado e baço de camundongos inoculados com $P$. brasiliensis são semelhantes aos descritos na literatura para vários animais experimentais como cobaios, ratos brancos, hamsters e camundongos 28915 .

$O$ início do tratamento, depois de 15 dias de inóculo resultou em estudos prévios em que se consegue a infectividade do animal após este período 6 15. Obteve-se nos animais estudados uma doença crônica, granulomatosa que envolve principalmente os órgãos do sistema retículo endotelial.

A grande quantidade de células fúngicas presentes nos animais infectados em contraste com aqueles infectados e tratados mostra mais uma vez que o cetoconazol é uma droga eficaz no tratamento da paracoccidioidomicose.

A resposta da imunidade mediada por células através de teste cutâneo feito na pata do animal mostrou-se positiva em $96,7 \%$ dos animais infectados. Defaveri e cols ${ }^{5}$ encontraram 78,6\% de positividade frente ao antígeno específico em camundongos infectados com $P$. brasiliensis. Sabese que esta resposta depende da quantidade e via de administração do inóculo, da virulência e antigenicidade do parasita.

A formação da resposta inflamatória granulomatosa foi praticamente igual em todos os animais, mostrando que a própria célula fúngica estimulou o aparecimento desta resposta, não se verificando ação do cetoconazol nas dosagens de 50 e $100 \mathrm{mg} / \mathrm{kg}$ com relação a produção de granulomas nos animais estudados. 
Silva MRR, Paiva LF, Jesuino RSA. Avaliação do cetoconazol em camundongos inoculados com Paraccoccidioides brasiliensis pela histopatologia de figado e baço e pela intradermorreação de paracoccidioidina. Revista da Sociedade Brasileira de Medicina Tropical 27:11-14, jan-mar, 1994.

\section{SUMMARY}

Male albino mice were inoculated intravenously with $0,5 \times 10^{7}$ viable yeast forms of $\mathrm{P}$. brasiliensis (strain 2052). These animals were treated with two doses of ketoconazole (50 and $100 \mathrm{mg} / \mathrm{kg}$ ) during fifty days and the sacrificed. We studied the presence of $\mathrm{P}$. brasiliensis, the inflammatory granulomatous response of liver and spleen and the anti $\mathrm{P}$. brasiliensis delayed hypersensitivity response measured by the footpad test after 48 hours. It was observed that: 1 . animals infected and treated with ketoconazole showed reduction in the number of fungi in the organs studied; 2 . there was no difference in the number of granulomas among animals treated and nontreated; 3. the cutaneous delayed tests intensity was similar in all animals.

Key-words: Paracoccidioides brasiliensis. Cellular imune response. Ketoconazole. Paracoccidioidine.

\section{REFERÊNCIAS BIBLIOGRÁFICAS}

1. Alves LM, Figueiredo F, Brandão Filho SL, Tincani I, Silva CL. The role of fractions from $P$. brasiliensis in the genesis of inflamatory response. Mycopathology 97:3-7, 1987.

2. Brito T, Fava Neto C. Disseminated experimental south American Blastomycosis of the guinea pig: a pathologic and immunologic study. Pathology and Microbiology 26:29-43, 1963.

3. Calich VLG, Singer-Vermes LM, Siqueira AM, Burger E. Susceptibility and resistance of inbred mice to $P$. brasiliensis. British Journal of Experimental Pathology 66:585-594, 1985.

4. Casotta M. Characterization of the cellular antigens of Paracoccidioides brasiliensis yeast form. Journal of Clinical Microbiology 28:1188-1193, 1990.

5. Defaveri J, Reskallah-Iwassa MT, Franco MF. Experimental pulmonary paracoccidioidmycosis in mice. Morphology and correlation of lesions with humoral and cellular immune response.
Mycopatologia 77:3-11, 1982

6. Fialho F, Gonçalves AP. Contribuição ao estudo da blastomicose brasileira. Estudo experimental desta micose no cobaio. O Hospital 30:397-407, 1946.

7. Franco M, Montenegro MRG. Relação parasitahospedeiro na paracoccidioidomicose. Revisão da literatura. Revista de Ciências Biomédicas 7/8:4760, 1987.

8. Guimarães N. Infecção do hamster (Cricetus auratus, Water-house) pelo agente da micose de Lutz (Blastomicose Sul Americana). O Hospital 15:515$520,1951$.

9. Kerr IB, Araripe JR, Oliveira PC, Lenzi HL. Paracoccidioidomycosis: a sequencial histopathologic study of lesions in experimentally infected rats. Revista do Instituto de Medicina Tropical de São Paulo 30:336-350, 1988.

10. Kerr IB, Silva AMM, Drouhet E, Oliveira P, Costa SCG. Paracoceidioidomycosis in nude mice. Presence of filamentous forms of the fungus. Mycopathologia 101:3-11, 1988.

11. Lima NS, Valle ACF. Ketoconazol na paracoccidioidomicose com longo seguimento pós terapêutico. Anais Brasileiros de Dermatologia 62:205-207, 1987.

12. Mendes $E$. Delayed hypersensivity reactions in patients with paracoccidioidomycosis. Proceeding of the Third International Conference on the Mycoses. Scientific Public 305:17-22, 1975.

13. Musatti CC. Cell mediated immunity in patients with paracoccidioidomycosis. Proceeding of the Third International Conference on the Mycoses 305:23$29,1975$.

14. Negroni R. Ketoconazol in the treatment of paracoccidioidomycosis and histoplasmosis. Fifth International Conference on the mycoses superficial, cutaneous and subcutaneous infections. PAHO. Scientific Public 396:361-365, 1980.

15. Silva MRR. Ação da anfotericina $B$ e levamisole em camundongos albinos inoculados com Paracoccidioides brasiliensis. Revista do Instituto de Patologia Tropical 11:173-217, 1982. 